\title{
DIRETRIZES PARA DURABILIDADE DE ESTRUTURAS DE CONCRETO ARMADO EM AMBIENTES COM ELEVADA CONCENTRAÇÃO DE CLORETOS
}

\author{
IBIAPINA, JUAN \\ Engenheiro Civil \\ Universidade Federal do Ceará \\ Ceará; Brasil \\ ibiapinajuan@gmail.com
}

\author{
PEREIRA, TALLYS \\ Engenheiro Civil \\ Universidade Federal do Ceará \\ Ceará; Brasil \\ tallyspereira18@gmail.com
}

\section{RESUMO}

Com o desenvolvimento da mistura de cimento Portland e inúmeros aditivos, principalmente no decorrer do século XX, foi possível aprimorar a resistência do concreto, possibilitando o alcance de grande resistência à compressão com menor uso de cimento, fator que auxiliou na redução das dimensões das peças. Esse motivo, aliado ao baixo cobrimento especificado no projeto e a grande variação de qualidade de execução das obras abriu espaço para um índice maior de manifestações patológicas. Logo, a questão da durabilidade tem ganhado força nos últimos anos, já que antes mesmo de atingir a vida útil de projeto as estruturas já se mostram deterioradas. Grande parte desse ganho de importância se deve, infelizmente, a acidentes fatais durante manuntenções preventivas e corretivas, e também aos altos custos globais de reabilitação de estruturas, tanto por projetos quanto por execuções deficientes. O trabalho revê brevemente as condições ambientais de Fortaleza que a fazem ser destaque no âmbito de agressividade ambiental devido aos cloretos. Além disso, são reunidas recomendações para o projeto e recuperação de estruturas de concreto armado inseridas no ambiente agressivo citado, como início de um trabalho de modelagem de uma edificação a ser realizada em software, para obter uma estimativa do carregamento e com base no estado dos elementos estruturais, prosseguir-se com um laudo da estrutura e projeto de recuperação. $\mathrm{O}$ presente estudo se baseia em uma revisão bibliográfica das contribuições de pesquisas de vários autores que dissertaram acerca de cada tema abordado, de maneira a contribuir com a disseminação do conhecimento e sendo breve guia sobre projetos de obras duráveis, portanto mais sustentáveis.

Palavras-chave: concreto armado, cloretos, durabilidade, guia, recuperação.

\section{ABSTRACT}

With the development of the Portland cement mix and the many additives, mainly during the 20th century, it was possible to improve the concrete resistance, making it possible to achieve high compressive resistance with less content of cement, causing a significant reduction in the dimensions of the structural pieces. This factor, combined with the low coverage of bars specified in the project and the big variation in the quality of the construction execution, made it possible arise a higher rate of weak points. Thus the question of durability has gained attention in recent years, since even before reaching the useful life of the design, the structures are already deteriorating. Much of this gain in importance has unfortunately been due to fatal accidents during preventive and corrective maintenance and also to the high global costs of rehabilitating structures, both for projects and for poor execution. The paper briefly reviews the environmental conditions in Fortaleza that make it stand out in the context of environmental aggressiveness due to chlorides. In addition, recommendations are gathered for the design and recovery of reinforced concrete structures inserted in the aggressive environment, such as the beginning of a building modeling work to be made in software, carrying out an estimate of the loading and based on the state of the elements. structural, proceed with a report of the structure and recovery project. The present study was based on a bibliographic review of research contributions by various authors who spoke about each topic addressed, in order to contribute to the dissemination of knowledge and to be a guide on durable, therefore more sustainable structural designs.

Keywords: chloride, durability, guide, reinforced concrete, repair. 


\section{INTRODUÇÃO}

Em construções antigas, o concreto apresenta resistência mecânica menor, quando comparada as edificações atuais. Em Fortaleza, por exemplo, o edifício da FIEC (Federação das Indústrias do Estado do Ceará) com o projeto datado de 1985, os pilares apresentam resistência a compressão da ordem de $15 \mathrm{Mpa}$, quase metade da resistência utilizada em projetos de edificações atuais, fato que ilustra o rápido desenvolvimento da tecnologia. Além disso, para a possibilidade de atender o grande vão solicitado na época, foi utilizada uma solução bem inteligente, a laje utilizada no projeto foi uma laje de tabuleiro de ponte sobre uma viga caixão. Esses fatores constituem como os principais motivos para a grande massa e elevado momento de inércia das peças, tanto devido ao conhecimento mais limitado da época sobre a tecnologia do concreto, quanto aos elevados coeficientes de segurança.

Com a evolução dos estudos, a qualidade dos materiais aumentou, foram desenvolvidas melhorias para a mistura de cimento Portland, como exemplo, a otimização da dosagem e a introdução de novos aditivos, tanto orgânicos quanto minerais. Tais aperfeiçoamentos contribuíram para o alcance dos requisitos de resistência à compressão com uma menor quantidade de cimento. Aliando o desenvolvimento dos materiais, com a evolução dos métodos de cálculo e melhorias nas técnicas executivas, foi possível uma redução nas dimensões das peças.

Esses fatores acompanhados à grande variação da qualidade de execução em algumas obras e a falta de uma manutenção coerente, possibilitou um maior índice de manifestações patológicas. $\mathrm{O}$ aparecimento de danos excessivos gera custos de reparos muito elevados, dessa maneira, a durabilidade passou a ser compreendida com a mesma cautela que as propriedades mecânicas e custo inicial. Cánovas (1988) menciona que tanto construtores como a administração pública estão conscientes de que a qualidade não é importante apenas para o prestígio e respaldo técnico, a qualidade é rentável a curto e longo prazo, portanto a realização de projetos de obras duráveis, auxilia no consumo consciente, ou seja, ajuda a sociedade a ser mais sustentável.

Atualmente, o bom desempenho, além de ser uma condição de satisfação dos clientes, é um recurso também utilizado para a redução dos custos globais da obra, resultado da adequação às novas culturas de qualidades impostas pela NBR 15575 (ABNT, 2013). A norma de desempenho de edificações tratou de organizar e formalizar os requisitos de desempenho para edificações habitacionais, de forma a inserir não só as exigências dos usuários ao conforto, como também a durabilidade, as informações do uso e manutenção. Já a NBR 6118 (ABNT, 2014) faz considerações sobre certas exigências para a durabilidade de estruturas. As interações estrutura-ambiente são tratadas em vida útil de projeto, mecanismos de envelhecimento e deterioração e agressividade ambiental. Os mecanismos de envelhecimento tratados são relativos ao concreto e à armadura, dentre os quais está o ataque por cloretos.

Por consequência, o estudo da durabilidade de estruturas de concreto em ambientes agressivos se torna necessário para mitigar as consequências dos atores patológicos inerentes ao ambiente. Diversas capitais brasileiras se encontram em ambiente litorâneo agressivo. Segundo a literatura mais recente, Albuquerque e Otoch (2005), Campos (2016) e Portella (2013), Fortaleza surge como grande destaque no tema agressividade do ar atmosférico, considerando as altas concentrações de íons de cloro, velocidades dos ventos, temperaturas e umidades ao longo de todo o ano.

Para o processo de construção e manutenção edifícios, o conceito de que o concreto é infinitamente durável ainda não está totalmente desmistificado. O oposto ocorre em estruturas como pontes e estruturas "off-shore" que tem seus mecanismos de deterioração bem controlados e planos de manutenção bem definidos, já que a paralização do uso da estrutura para execução de manutenções imprevistas, pode gerar irreparáveis perdas econômicas.

Para o reestabelecimento das condições iniciais das estruturas degradadas devido às agressões dos íons cloreto, surge a recuperação de estruturas, que aborda a determinação da capacidade resistente residual, as técnicas e os materiais utilizados no processo, ramo que está em constante desenvolvimento, tendo em vista os seus altos custos.

Para o cálculo de reforços, a NBR 6118 (ABNT, 2014) não possui qualquer orientação. Por esse motivo, os projetos de reforços são feitos baseados na experiência do engenheiro projetista. Devido ao elevado custo, a deterioração prematura devido ao ataque por cloretos é um dos principais vilões do custo global da obra, principalmente pelo descaso com as inspeções e as manifestações patológicas, sendo executados simples reparos ou recuperações que não são condizentes com a real necessidade da estrutura, às vezes titulados como "indústria do reparo do reparo".

A solução dos problemas de deterioração precoce, como a danificação por ataques químicos, ainda se caracteriza como um grande desafio, além de ameaçarem muitas estruturas de concreto. Autores como Gjørv (2015) e Andrade (1997) 
citam o que aparenta ser a mais grave ameaça à durabilidade e ao desempenho de muitas estruturas de concreto: a corrosão das armaduras devido ao ataque por cloretos.

O objetivo desse estudo é apresentar a importância do conhecimento das condições ambientais do local da construção e apresentar um breve roteiro para a elaboração do projeto e de recuperação de estruturas de concreto armado inseridas em ambientes com elevada concentração de cloretos.

\section{EVOLUÇÃO DO COMPORTAMENTO DAS EDIFICAÇÕES}

\subsection{Vida útil e durabilidade}

Para Metha e Monteiro (2014), longa vida útil é sinônimo de durabilidade, sendo a variação resultado das interações entre o ambiente e os materiais, visto que são alteradas a microestrutura e as propriedades ao longo do tempo. Entre os vários conceitos de durabilidade, o apresentado pelo CEB-FIC MC-90 (1991) apresenta uma definição mais geral. De acordo com esse código, as estruturas devem satisfazer critérios de projeto, execução e utilização, a fim de que, sob condições ambientais conhecidas, mantenham-se seguras, estética e funcionalmente aceitáveis.

Em Helene (2004), o conceito citado é dividido em etapas. A primeira refere-se ao período de tempo em que os agentes agressivos atuam até a despassivação da armadura, sendo nomeada de período de iniciação, esse período é associado ao termo vida útil de projeto, sendo tomado com segurança, já que o fato da frente de cloretos atingir a armadura não significa corrosão excessiva, e sim que foi dado o início do processo de corrosão. A segunda etapa é o período em que aparecem manchas, fissuras ou até destacamento superficial do concreto, denominado vida útil de serviço (1 e 2). Nesse contexto, na terceira tem-se o período em que se dá a falha parcial ou total da estrutura, e está relacionada ao período em que há grande redução da seção resistente ou redução da aderência entre armadura/concreto. Associa-se esse período à vida última ou total. Finalmente, a quarta etapa é denominada de vida residual, sendo um tanto subjetiva, nela a estrutura ainda é capaz de desenvolver suas funções, mesmo estando muito deteriorada. O período residual é iniciado a partir de uma vistoria ou possível intervenção na estrutura. A Figura 1 apresenta um gráfico esquemático das etapas.

Figura 1- Vida útil das estruturas

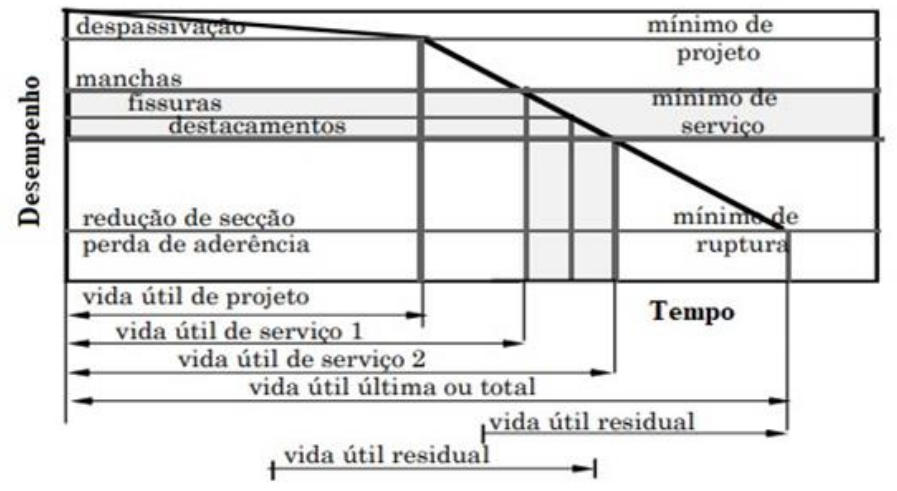

Fonte: Helene (2004, com adaptações)

\subsection{Ataque por cloretos}

Segundo Cánovas (1988), ações do tipo químico são as que causam maior dano na estrutura, pesquisadores como Neville (1997) e Metha e Monteiro (2014) esclarecem que a deterioração tanto do concreto como do aço é, normalmente, atribuída a mais de um fator, sendo a corrosão do metal, a principal.

Nesse contexto, autores como Cascudo (1997), Helene (2004) e Cabral (2000), afirmam que o ataque por cloretos é a principal causa da corrosão. Segundo esses autores, ao ingressar no interior do concreto, o cloreto rompe uma fina película de passivação, camada de óxido que adere ao aço e fornece boa proteção contra água e oxigênio. Após a destruição dessa camada, a alcalinidade do concreto é reduzida e é formada uma diferença de potencial elétrica entre dois pontos no aço e no concreto, formando uma célula eletroquímica. Helene (2004) explana em seus estudos que devem existir três condições básicas para a ocorrência da corrosão, sendo elas: deve existir um eletrólito; deve ser formada uma diferença de potencial; e deve existir oxigênio. 
Com esses elementos básicos, Cascudo (1997) exemplifica que a corrosão da armadura na zona anódica ocorre devido às reações que realizam a dissolução do ferro, nas zonas catódicas, as não corroídas, ocorrem as reações de redução. Íons $\mathrm{Fe}^{2}+$ se deslocam em direção ao cátodo e os íons de hidroxila, $\mathrm{OH}-$, se deslocam em direção ao ânodo, encontrando-se em uma região intermediária, produzindo hidróxido ferroso $\left(\mathrm{Fe}(\mathrm{OH})_{2}\right)$. A partir do hidróxido ferroso, podem ser formados produtos expansivos como o óxido férrico hidratado, $\mathrm{Fe}_{2} \mathrm{O}_{3} \mathrm{H}_{2} \mathrm{O}$, sendo esse composto muito expansivo. A Figura 2 mostra os esforços produzidos pela expansão do aço. Neville (1997) destaca que os produtos da corrosão, expansivos, ocupam um volume muito maior do que o aço, desse modo, ocorre a fissuração e o lascamento do concreto.

Figura 2 - Esforços envolvidos no processo

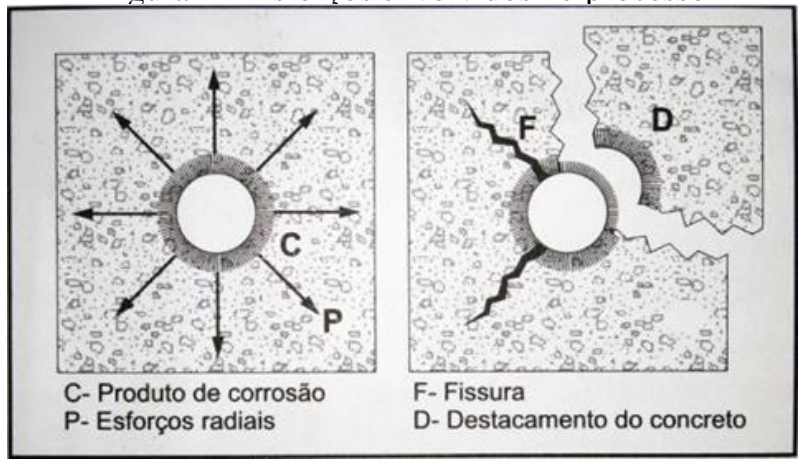

Fonte: Cascudo (1997)

\subsection{Avaliação do grau de deterioração}

Processos de análise de vida útil, além de muitas variáveis, contém processos aleatórios que proporcionam certa imprecisão na determinação da vida útil. Possan (2010) ressalta a limitação de processos determinísticos, como a segunda Lei de Fick, em que considera o coeficiente de difusão constante com o tempo, sendo que em verificações experimentais esse coeficiente reduz com o tempo, portanto modelos estocásticos se tornam interessantes quando se quer considerar incertezas na estimativa da vida útil, cabendo citar que não há um modelo de previsão de vida útil amplamente difundido no Brasil.

Dentre as várias abordagens para a determinação da vida útil das estruturas, um modelo que pode ser empregado fraciona o processo de degradação em 2 partes. Na primeira, denominada estágio de iniciação, ocorre a penetração do cloreto no concreto, porém sem causar dano a armadura, enquanto a segunda é o estágio de propagação, em que as primeiras manifestações na estrutura do concreto aparecem. A Figura 3 mostra as fases de degradação relativa ao grau de deterioração do aço.

Figura 3 - Processo de degradação

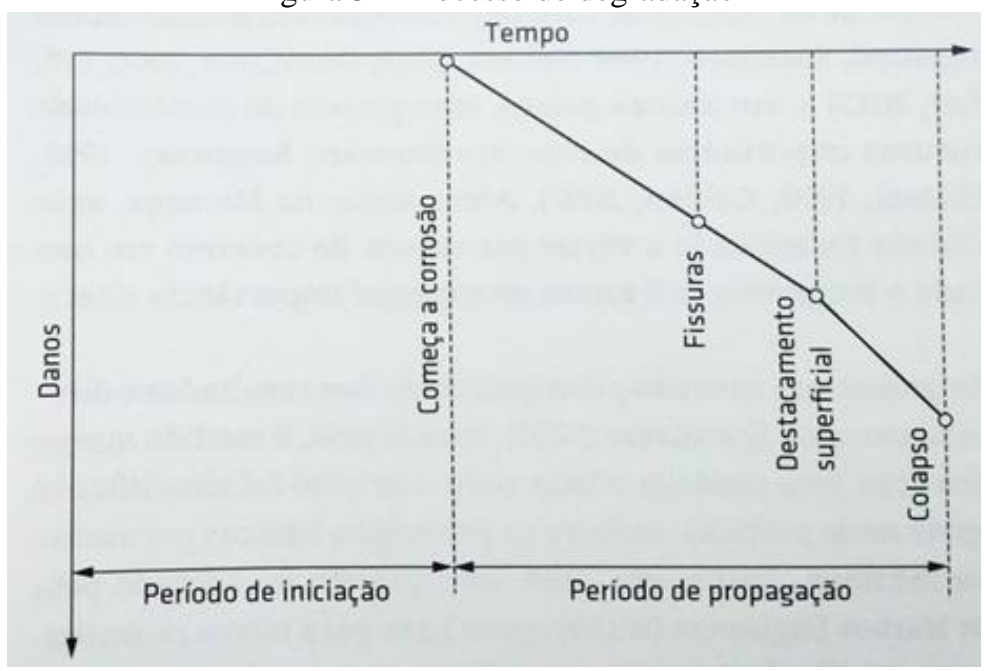

Fonte: Gjørv (2015) 
Todo o processo de corrosão é bastante complexo, desse modo é difícil desenvolver um modelo matemático generalizado para antecipar o tempo necessário para reduzir a capacidade portante da estrutura, tendo em vista que a forma do elemento, continuidade elétrica e exposição influenciam no processo. Um modelo determinístico citado por Ibiapina (2019) usado na etapa de iniciação é a $2^{\circ}$ Lei de Fick, que é usada para determinar a taxa de penetração do cloreto em certa profundidade no elemento estrutural, em um determinado tempo.

A equação desse modelo determinístico segundo Dal Molin e Silvestro (2018) está representada a seguir:

$$
\mathrm{C}(\mathrm{x}, \mathrm{t})=\mathrm{Cs} *\{\operatorname{erfc}[\mathrm{x} /(4 * \mathrm{t} * \mathrm{D}) 0,5]\}
$$

Onde,

$\mathrm{C}(\mathrm{x}, \mathrm{t})$ - Concentração de cloretos na profundidade $\mathrm{x}$ a partir da superfície do concreto em um dado tempo $\mathrm{t}(\%)$; Cs - Concentração superficial de cloretos (sendo admitida como constante) (\%);

$\mathrm{x}$ - Profundidade $(\mathrm{cm})$;

$\mathrm{D}$ - Coeficiente de difusão de cloretos( $\left.\mathrm{cm}^{2} / \mathrm{ano}\right) ; \mathrm{t}$ - Tempo (anos);

erfc - Função complementar de erro de Gauss.

\section{CONDIÇÕES AMBIENTAIS DO LOCAL DA EDIFICAÇÃO}

\subsection{Aspetos gerais}

Para Ibiapina (2019) o conhecimento da agressividade do ambiente marinho já é bem consolidado. A influência desse ambiente na longevidade das estruturas está sujeita ao microclima no qual a edificação está inserida, de forma que o ambiente marinho pode atuar desencadeando reações de deterioração amplamente estudadas, a exemplo dos estudos de Gjørv (2015) que discorrem sobre a tradição da Noruega no uso de concreto em estruturas implantadas em ambiente marinho, consequência de possuir um litoral longo e irregular.

Cánovas (1988) cita como fator fundamental para mitigar as ações agressivas do ambiente a adoção de medidas profiláticas logo na etapa de projeto, conhecidas as condições ambientais particulares da região.

Nesse contexto, Andrade (1997) aponta para a importância da análise da agressividade ambiental baseada em dados e registros meteorológicos. Ela constitui como fator fundamental para prever a durabilidade das estruturas de concreto, sendo um compromisso que deve ser firmado como parte do planejamento da edificação. São exemplos os estudos recentes da agressividade do ar atmosférico em Fortaleza, desenvolvido por Campos (2016), Albuquerque e Otoch (2005) e Portella (2013).

O Brasil ostenta ampla costa marítima banhada pelo Oceano Atlântico, segundo o IBGE (2014), a extensão era de 7367 km, tendo o Nordeste como destaque no quesito agressividade, em especial, a cidade de Fortaleza como cidade portuária. Fortaleza está situada no nordeste brasileiro e é a capital do estado do Ceará. O clima é tropical com temperatura anual média de $26.5^{\circ} \mathrm{C}$. A cidade possui um total de 15 praias, com $34 \mathrm{Km}$ de extensão no total, todas contribuindo para a disseminação de íons cloro na atmosfera.

\subsection{Temperatura}

Sabe-se que o aumento da temperatura provoca um aumento na velocidade de degradação, pesquisas de Geho-CEB (1993) apud Vilasboas (2013) verificam que um incremento de $10^{\circ} \mathrm{C}$ na temperatura dobra a velocidade das reações vinculadas à degradação da estrutura de concreto armado. Logo, esse motivo faz com que os ambientes tropicais sejam bem mais agressivos que os temperados no norte da Europa. Segundo Portella (2013) a temperatura de Fortaleza situase na média em torno de $26^{\circ} \mathrm{C}$ a $28^{\circ} \mathrm{C}$ e possui grande amplitude térmica, $23^{\circ} \mathrm{C}$ a $32^{\circ} \mathrm{C}$.

\subsection{Umidade}

López, González e Andrade (1993) reiteram que, em ambientes secos, a vida útil de estruturas cresce com a elevação da temperatura, devido à perda do eletrólito, o que dificulta a corrosão. Desse modo o efeito da temperatura não pode ser considerado isolado, devendo ser correlacionado com a temperatura. Segundo a Fundação Cearense de Meteorologia (FUNCEME) a umidade média de Fortaleza é superior a 70\%, chegando até $80 \%$ em algumas épocas do ano. 


\subsection{Velocidade dos ventos}

A formação do aerossol marinho está diretamente ligada à velocidade dos ventos e à concentração de sais no aerossol. Estudos indicados por Pontes (2006) demonstram que esta relação segue uma função do tipo exponencial. Lovett (1978) apontou que esse comportamento é devido ao fato de que o aumento da velocidade dos ventos provoca um aumento na quantidade de partículas no aerossol e facilita a produção de elementos de maior massa. A Figura 4 mostra essa relação.

Figura 4 - Esauema da concentracão de sais com a velocidade do vento

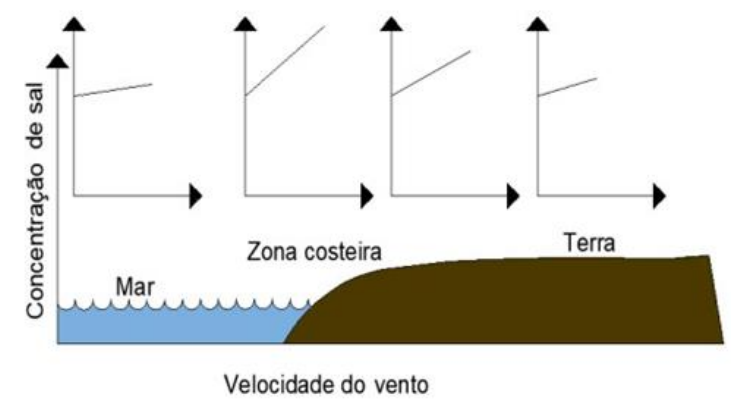

Fonte: Gustafson e Franzen (1996, com adaptações)

No quesito velocidade dos ventos, vários autores buscaram uma velocidade crítica, a partir da qual a formação e o transporte de partículas maiores se tornariam relevantes, ocasionando maior concentração de cloretos na atmosfera. A Tabela 1 faz um resumo de algumas velocidades críticas adotadas por diferentes autores, e nela admite-se o valor de $3 \mathrm{~m} / \mathrm{s}$ como o mais aceito pelos autores. Estudos de Campos (2016) aferiram a direção predominante dos ventos em Fortaleza como sendo de leste e sudeste, adentrando pela Praia do Futuro. A velocidade média aferida foi de 3,6m/s, ou seja, maior que a velocidade crítica adotada.

Tabela 1- Velocidade crítica adotada pelos autores consultados.

\begin{tabular}{c|c}
\hline Autor(es) & Velocidade crítica \\
\hline Piazzola e Despiau (1997) & $>5 \mathrm{~m} / \mathrm{s}$ \\
\hline Fitzgerald (1991) & $>3 \mathrm{~m} / \mathrm{s}$ \\
\hline O' Dowd et al. $(1996)$ & $>3 \mathrm{~m} / \mathrm{s}$ \\
\hline
\end{tabular}

\subsection{Distância do mar}

Gustafsson e Franzén (1996) apud Pontes (2006) relatam que a influência do vento na concentração de sal na atmosfera diminui à medida que se afasta do mar, tanto devido aos obstáculos na costa como o efeito gravimétrico que se sobressai ao efeito do vento.

\subsection{Climatologia de Fortaleza}

Dessa forma, conclui-se que, devido à combinação desses fatores, junto com ciclos de umedecimento e secagem, grandes períodos de insolação e grandes correntes de ventos constituem fatores para que a cidade de Fortaleza tenha condição climática ideal para o processo de corrosão das armaduras.

\section{RECOMENDAÇÕES PARA O PROJETO E RECUPERAÇÃO DE ESTRUTURAS}

\subsection{Aspectos gerais}

Neste item, serão abordados, de forma sucinta, alguns dos materiais e procedimentos mais abordados na literatura consultada para o projeto e recuperação de estruturas de concreto armado em ambientes com alta incidência de cloretos, com o objetivo de possibilitar uma utilização precisa, com base em diagnóstico prévio executado.

Os ataques por íons de cloreto podem ter início no momento em que o concreto é produzido ou através do meio ambiente. Cabral (2000) e Barbosa et al. (2004) citam o uso de agregados contaminados, aditivos aceleradores de pega composto por cloretos e água contaminada como exemplos de contaminação no momento do amassamento, mas que 
esse último é raramente detectado em dias atuais, por conta dos avanços científicos sobre os males provocados por essas ações. Em vista disso, a maior parte dos problemas são devidos ao ingresso do cloreto através do meio ambiente.

Se a solução não for tratada na etapa de projeto, o custo de adiar o tratamento das patologias progredirá cada vez mais ao longo do tempo. O custo dessa intervenção pode ser representado pela Lei de Sitter ou Lei dos 5, representada na Figura 5. Para critério de elucidação o custo de uma manutenção corretiva na etapa de uso, poderá ser até 125 vezes maior que o custo da solução na etapa de projeto.

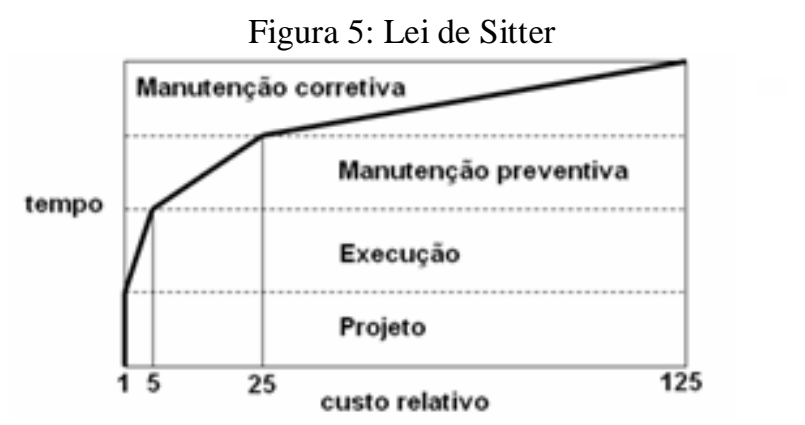

Fonte: Sitter (1984) apud Helene (2004, com adaptações)

Quando se comenta sobre falhas ocorridas na etapa de projeto, logo é associado ao fato de erros de cálculo terem sido praticados, mas de acordo com Somerville (1985) apud Andrade (1997), erros de cálculo raramente são a raiz do problema, o que geralmente ocorre é um detalhamento deficiente, falta de atenção ou negligência ao meio ambiente em que a estrutura se localizará, como também a interação entre os tipos de elemento que compõe a estrutura, representado pela Figura 6, em que a falta de detalhamento e inadequação da peça ao ambiente causa sérios danos ao longo do tempo.

Figura 6: Ausência de detalhamento de pingadeira pela falta de atenção ao ambiente
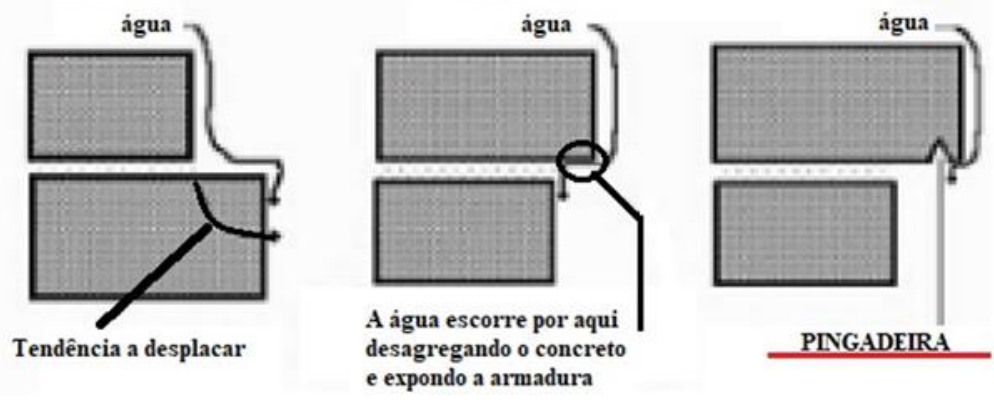

Fonte: Souza \& Rippier (2009, com adaptações)

\subsubsection{Relação água/cimento, grau de hidratação e tipos de cimento}

Segundo Metha e Monteiro (2014), a permeabilidade é a chave para limitar os processos corrosivos, a dosagem da relação a/c para determinadas condições de agressividade é importante tanto para a resistência quanto para a redução da permeabilidade, não sendo recomendada ser maior que $0,40 \mathrm{em}$ cimentos Portland puros, devido ao aumento da porosidade.

A escolha do tipo de cimento tem vital importância, já que combinando cimentos com altos teores de escória e uma variedade de materiais pozolânicos, são alcançadas baixas taxas de difusividade, produzindo concretos com alta resistência a cloretos. Ibiapina (2019) cita pesquisas que mostram que cimentos com escória de aciaria (CP II E 40), e cimentos com adições de cinzas volantes (CP II Z 40), quando comparados a cimentos Portland puros (CP V) apresentam difusividade significativamente menor.

\subsubsection{Processos construtivos}

A execução dos procedimentos visando a durabilidade, como verificação do cobrimento, adensamento e cura são de grande importância para o bom desempenho da estrutura, um adensamento mal executado pode refletir e um concreto mais poroso, enquanto a cura insuficiente, produz baixo grau de hidratação no concreto, deixando-o mais permeável. 
Uma boa solução para o controle de qualidade seria a adoção de elementos estruturais pré-fabricados, já que seu processo de fabricação é bem controlado e não há possibilidade de exposição precoce ao cloreto. Ainda existe a facilidade do emprego de sistemas de proteção superficial, aguardando sua secagem antes da exposição da peça.

Também deve-se dedicar tempo na elaboração de um plano de manutenção completo da estrutura, manual que tem ligação com o ambiente e nível de sensibilidade da estrutura, devendo conter anotações sobre o comportamento da estrutura, realizadas através das inspeções de rotina.

\subsubsection{Proteção do concreto e da armadura}

Nos últimos anos tem surgido produtos para a proteção da superfície do concreto, tanto para redução do teor de umidade do concreto, como para prevenir a penetração dos cloretos. Gjørv (2015) agrupa os materiais de proteção em 4 categorias: revestimentos orgânicos, que formam uma fina película sobre o concreto; tratamentos hidrofugantes, focados no revestimento da superfície interna dos poros do concreto; terapias que preenchem os poros do material, e tratamentos com uma camada cimentícia espessa e densa. A Figura 7 resume o funcionamento desses tipos de proteção.

Figura 7: Representação dos diferentes tipos de proteção superficial do concreto

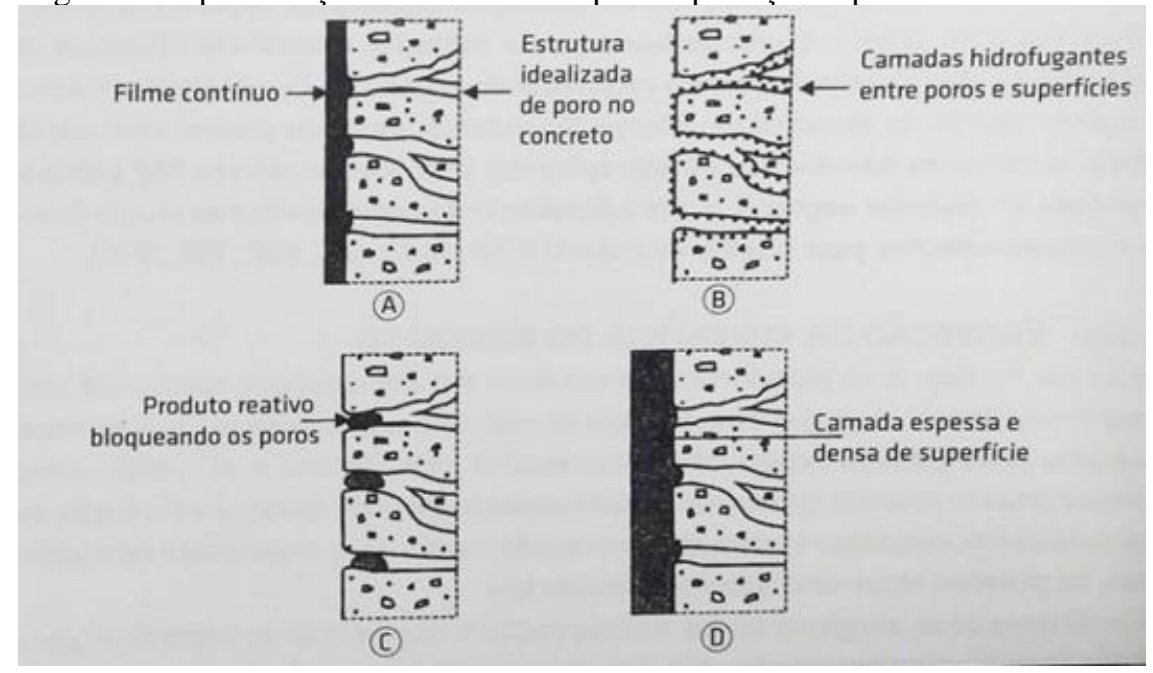

Fonte: Gjørv (2015)

Inibidores de corrosão podem ser especificados tanto na etapa de projeto quanto na etapa de recuperação da estrutura, Brett e Brett (1996) os define como substãncias orgânicas ou inorgânicas que acrescidas à mistura do concreto em concentração reduzida, diminui a velocidade de corrosão. Em Gjørv (2015) é citado uma vasta gama de pesquisas com o uso dessas substâncias, sendo o mais testado e aplicado, o nitrato de cálcio. Além de prevenir, ele reduz a taxa de corrosão, outros autores, como Page (2002), fazem ressalvas para aplicação dessa substância, afirmando que ao longo do tempo o nitrato de cálcio será consumido, dessa forma é complicado de garantir o efeito ao longo prazo.

\subsection{Recuperação de estruturas atacadas por cloretos}

Para a recuperação de estruturas atacadas por cloretos é necessário remover todo o íon cloreto, visto que eles não são consumidos nas reações e ficam livres para continuar a corrosão após o término do processo reativo. Estudos de Helene (2004) confimam, já que recomendam a limpeza da região, principalmente as cavidades do aço, em que se concentra a corrosão por pites, pois é nela que os ácidos e os cloretos se concentram. Caso não haja a remoção total no momento do reparo, o novo concreto não será capaz de repassivar a armadura.

\subsubsection{Estratégias de intervenção}

O objetivo básico do reparo é parar ou reduzir o processo corrosivo, intervindo no processo catódico ou anódico ou na condução eletrolítica, processos responsáveis pela formação da célula de corrosão. Rilem (1994) apud Cabral (2000) resume as estratégias de intervenção em quatro grupos, sendo destacado três deles: Substituição ou reconstrução parcial dos componentes danificados, utilizado quando o dano é limitado aos elementos mais expostos as intempéries, podendo ser substituídos; intervenções que dificultam o processo corrosivo, regenerando as zonas de armaduras atingidas e a 
substituição do concreto afetado, e, finalmente, não intervir no processo de corrosão, adotando apenas medidas paliativas até que seu uso se torne insustentável.

\subsubsection{Sistemas de reparo atuantes sobre o concreto}

Para esse tipo de reparo, a literatura aborda os sistemas de reparo sobre repassivação, sistemas de reparo por barreira e sistemas de reparo por inibição.

Sistemas de reparo por repassivação do concreto são mais utilizados quando o agente iniciante da corrosão é a carbonatação, já que o desempenho do método é ruim quando a contaminação por cloretos é alta, pode ser utilizado como sistema auxiliar, como indica Cabral (2000). Já Helene (2004) alerta que esse método em certos casos pode deslocar as pilhas de corrosão, preservando apenas o trecho reparado e acelerando o processo de corrosão nas regiões adjacentes, inicialmente em bom estado.

Sistemas de reparo por barreira normalmente são usados como sistemas de reparo complementares a outro método. Vernizes base epóxi, base acrílica e revestimentos espessos e resistentes evitam a penetração dos íons cloreto, pois impermeabilizam a superfície do concreto, cabe destacar que a eficiência está ligada a aplicação em toda a superfície da peça afetada para barrar o oxigênio.

Inibidores de corrosão promovem alterações locais na região metal-eletrólito, provocando redução da corrosão. Essa técnica faz parte de um conjunto de medidas que são usadas para diminuir a corrosão, trabalha em grupo com um bom projeto, materiais bem especificados, boa execução e um plano de manutenção coerente, com isso haverá a elevação da eficácia do inibidor.

\subsubsection{Sistemas de reparo atuantes sobre a armadura}

Para sistemas de reparo atuantes na armadura, dois são destacados: os sistemas de reparo por barreira sobre a armadura e os de reparo por proteção catódica.

Sistemas de reparo por barreira no aço tem os mesmos princípios do sistema de reparo por barreira no concreto, utilização de pinturas com baixa permeabilidade, atuando como barreira física, como esse sistema é aplicado diretamente sobre as armaduras, também pode deslocar as pilhas de corrosão para as regiões vizinhas da área reparada.

Cascudo (1997) separa os sistemas de reparo por proteção catódica em dois, o método galvânico e o método por corrente impressa. O mais usual para estruturas de concreto é o por corrente impressa.

São utilizados sistemas de ânodos em forma de tela junto a superfície do concreto, cobre-se esse sistema com uma camada de concreto, é feita uma interligação do ânodo ao terminal positivo de um retificador de corrente e as armaduras são conectadas ao terminal negativo. Ao ser ligado é estabelecida uma diferença de potencial entre a região anódica e o aço, logo as armaduras ficam protegidas por funcionarem como cátodos, a corrente atravessa o cobrimento de concreto chega as armaduras e retorna pelo ânodo do retificador, fechando o circuito. A Figura 8 ilustra o processo.

Figura 8: Processo de funcionamento do sistema de protecão catódica por corrente impressa

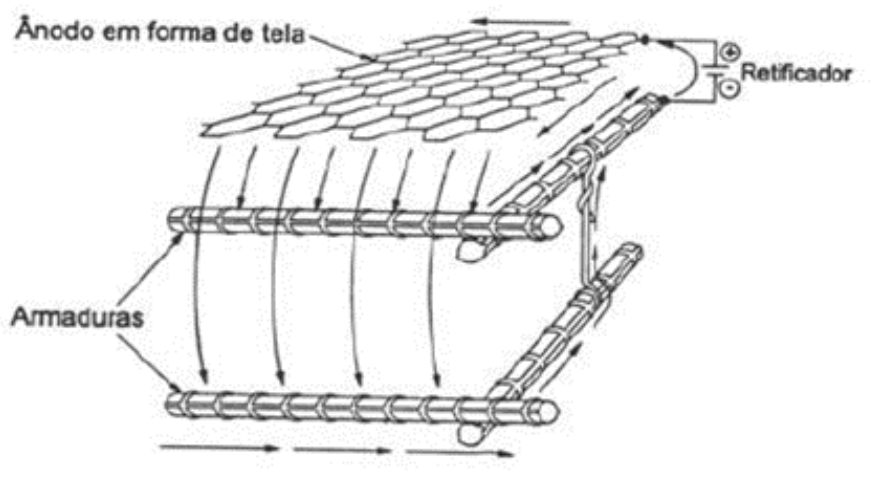

Fonte: Cascudo (1997) 


\subsubsection{Procedimentos}

Procedimentos para a recuperação de estruturas são vastamente discutidos na literatura por Souza e Rippier (2009), Helene (1992), Cánovas (1988), Lapa (2008) entre outros pesquisadores. Será descrito a seguir os procedimentos mais usados no reparo de estruturas afetadas por ação corrosiva devido aos íons cloretos.

Souza e Rippier (2009) recomendam uma investigação minunciosa dos elementos deteriorados, da extensão das avarias, determinação da capacidade resistente residual da peça, ligado ao grau de segurança da estrutura, a determinação ou não do uso de escoramentos, além da definição tipo de reforço ou reparo que irá ser utilizado.

Para o reparo das estruturas, Helene (1992) recomenda processos para o preparo do substrato. As tabelas a seguir os ilustram. Para a limpeza das superfícies, recomenda-se o jateamento de ar comprimido, já que ele pode ser utilizado com o concreto em condições secas ou úmidas.

Cánovas (1988) e Helene (2004) dividem a colocação do novo concreto em reparos localizados, reparos em grandes áreas, reparos rasos e profundos. Para reparos localizados recomenda-se o emprego de argamassas de cimento Portland ou resina epóxi, já para grandes áreas, a técnica do concreto projetado ganha eficiência. A técnica consiste em conduzir o concreto através de uma mangueira, conectada em um compressor, projetando o concreto em grande velocidade.

Tabela 2 - Resumo dos procedimentos Resumo dos procedimentos

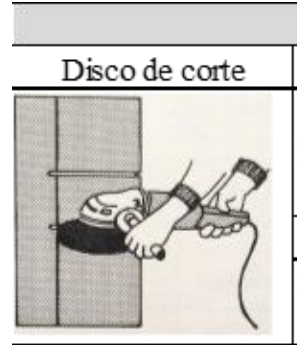
Procedimento - Adequado para aço e concreto

Manter o disco em posição ortogonal a superfície, tendo delimitado a área de execução antes do início do corte

Desvantagens

Requer o uso de mão de obra especializada e acessórios adequados, cuidado para não danificar estribos e armaduras não atingidas por cloretos

Escarificação manual

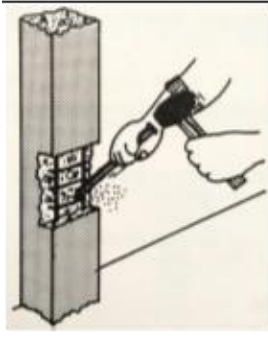
Procedimento - Adequado para concreto

A superficie deve ser escarificada de fora para dentro, deve ser retirado todo o material solto ou mal compactado até atingir o concreto são, propiciando uma superficie rugosa e coesa, para boas condições de aderância, prevendo cimbramento adequado, caso seja necessário

Baixo ruído e sem muita pœira e não exige mão de dbra especializada Desvantagens

Baixa produtividade, após a escarificação ainda deve ser feita uma limpeza na superfície para a remoção do pó, usualmente, ar comprimido

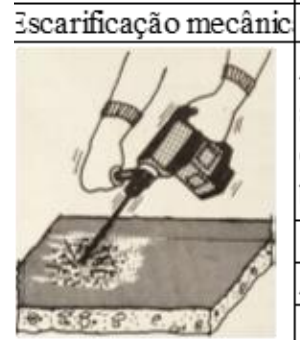
Procedimento - Adequado para o concreto

A superficie deve ser escarificada, de maneira a evitar o lascamento de arestas e cantos. Se tratando de superficies planas deve-se remover a nata superficial e fornecer rugosidade ao concreto, deve ser retirado todo o material solto ou mal compactado até atingir o concreto são, propiciando uma superficie rugosa e coesa, para boas condições de aderância, prevendo cimbramento adequado, caso seja necessário

\begin{tabular}{|c|c|c|}
\hline Vantagens \\
\hline Alta produtividade e não requer mão de obra especializada \\
\hline Desvantagens \\
\hline Baixa produtividade para espessuras menores que $1 \mathrm{~cm}$
\end{tabular}

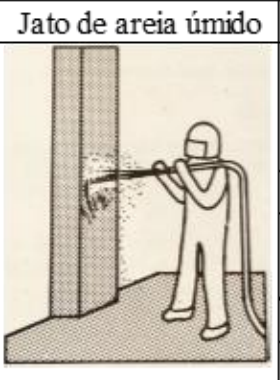

Procedimento - Adequado para aço e concreto

Manter o bico de jato em uma posição ortogonal à superficie de aplicação, a um metro de distância, $o$ movimento deve ser feito em círculos, de maneira a distribuir o material uniformemente e remover todos os resíduos que prejudicam a aderência

\section{Vantagens}

Prepara as superficies, eliminando as partículas soltas e removendo o material que possa vir a prejudicar a aderência, permite a limpeza da armadura, eliminando as camadas corroídas e ausência de pó com o jato úmido Desvantagens

Não remove frações de espessura maiores que $3 \mathrm{~mm}$, em alguns casos, não dispensa a escarificação prévia

Fonte: Helene (1992, com adaptações) 
Tabela 3 - Resumo dos procedimentos

\begin{tabular}{|c|c|}
\hline \multicolumn{2}{|r|}{ Resumo dos procedimentos } \\
\hline Disco de desbaste & Procedimento - Adequado para aço e concreto \\
\hline \multicolumn{2}{|r|}{$\begin{array}{l}\text { Aplicar o disco com lixa sobre a superficie, efetuando o desbaste em camadas ou passadas cruzadas a } 90^{\circ} \text {, } \\
\text { desbastar finas camadas por vez, mantendo a superficie uniforme }\end{array}$} \\
\hline \multicolumn{2}{|r|}{ Vantagens } \\
\hline & Alta produtividade \\
\hline & Desvantagens \\
\hline & Requer mão de obra especializada \\
\hline Lixamento elétrico & Procedimento - Adequado para aço e concreto \\
\hline & Manter a lixa paralela à superficie em tratamento, buscando efetuar movimentos circulares \\
\hline & Vantagens \\
\hline & $\begin{array}{l}\text { Remove as impurezas existentes na superficie do concreto, abrindo e limpando os poros, remove a carepa de } \\
\text { laminação e a crosta de corrosão superficial das chapas metálicas, permite a regularização da superficie e a } \\
\text { remoção de eflorecências. }\end{array}$ \\
\hline & Desvantagens \\
\hline & Provoca elevado grau de sujeira e poeira no ambiente, requer o uso de EPI's \\
\hline
\end{tabular}

Fonte: Helene (1992, com adaptações)

A literatura costuma diferenciar reparos rasos como reparos que possuem uma profundidade de até $2,5 \mathrm{~cm}$, a partir disso, são usadas terminologias como reparo semi-profundo e reparos profundos. Cabe ressaltar o cuidado necessário com a concretagem em reparos profundos, que necessitam ser preenchidos em camadas de até $3 \mathrm{~cm}$.

Para limpeza das armaduras e o preparo do substrato, Helene (1992) recomenda a limpeza das barras contaminadas com jatos de areia úmidos, para grandes áreas e lixamento ou escovamento manual para pequenas áreas. Após a definição da área a ser tratada, juntamente com a remoção do concreto deteriorado. Souza e Ripier (2009) recomenda o corte do concreto sempre que houver corrosão do aço das armaduras, para garantir a imersão em um ambiente alcalino, por isso, o corte deve ultrapassar as armaduras em $2 \mathrm{~cm}$, a Figura 9 ilustra o procedimento.

Figura 9: Corte recomendado além da armadura

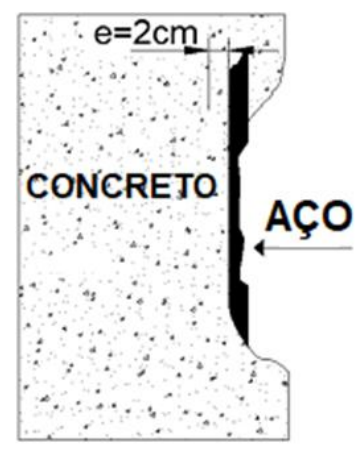

Após o exame das condições da armadura, é feita uma análise para determinar a recomposição ou não da área de aço corroída. Tem-se dois métodos básicos para decisão. O primeiro se a redução da seção da barra, ou somatório das áreas das barras, corroída tiver ultrapassado $15 \%$. O segundo se o diâmetro equivalente da barra corroída tiver perdido $10 \%$ do seu diâmetro inicial. Esses limites são bastante discutíveis, já que em alguns casos não devem ser utilizados, principalmente em situações críticas. Os métodos estão bem detalhados em Souza e Ripier (2009), com a especificação do comprimento de ancoragem necessário das novas barras, como também das emendas, essenciais para a transmissão dos esforços. A Figura 10 apresenta uma síntese do processo e uma sugestão de emenda por solda.

Após a limpeza das armaduras deverá ser aplicada tanto no aço como no concreto uma camada de resina epóxi, para incrementar a aderência com o concreto novo e criar uma região mais impermeável. O lançamento do novo concreto deverá ser feito com a camada de adesivo ainda fresca, já que, se a concretagem for feita com a camada seca, não haverá aderência entre os concretos. O lançamento do novo concreto poderá ser feito com as mesmas técnicas já apresentadas, como concreto projetado e o método tradicional, com a utilização de formas. 
Figura 10: Processo recomposição da área de aço original e exemplo de um processo de solda

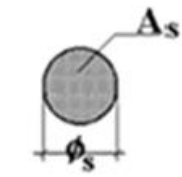

Situação original, ou de projeto

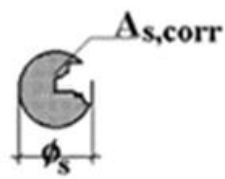

Situação existente, provocada pela corrosão

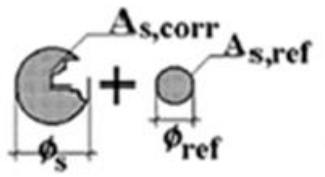

Situação de complementação, pela adição de novas barras
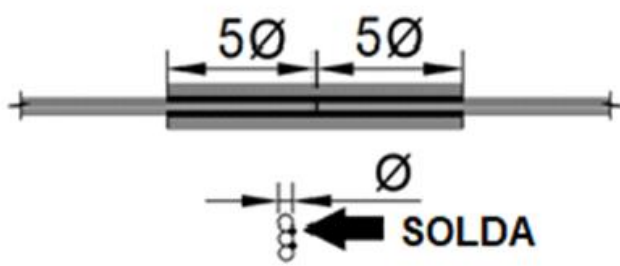

Fonte: Souza e Ripier (2009, com adaptações)

\section{APLICAÇÃO PRÁTICA}

Essa teoria foi aplicada para o projeto de recuperação de um edifío com cerca de 40 anos de idade localizado no bairro Aldeota em Fortaleza, para preservar o anonimato, não será identificado. Após a inspeção visual inicial, foram verificados danos severos por corrosão da armadura em algus elementos estruturais na região do pilotis. Foi verificado um cobrimento em média de $1 \mathrm{~cm}$ nos elementos, esse fato junto a vários problemas nas instalações hidráulicas, possibilitaram vazamentos que causaram danos severos em algumas vigas e lajes, os problemas nas instalações não afetaram os pilares, mas ainda sim alguns apresentavam sérios danos. Foi constatado que as lajes de alguns apartamentos apresentavam piso sobre piso e alguns moradores realizaram modificações como incremento de varanda, esses dois fatores aumentaram muito a sobrecarga. Foram realizados testes esclerométricos nos pilares, com isso obteve-se uma ideia da resistência dos pilares, auxiliando na tomada de decisão sobre o escoramento.

Para critério de classificação, os elementos foram classificados de 1 a 3, 1 para elementos com aparência externa íntegra ou início de desplacamento, 2 para elementos com perda de seção de até $20 \%$ e concreto desagregado com limite não superior ao cobrimento e 3 para elementos com perda de seção maiores que $20 \%$ e concreto desagregado passando do cobrimento, tendo a necessidade de adição de armadura. Além de repor a armadura deteriorada, aplicando a teoria apresentada, foi necessário efetuar o aumento da seção resistente, com encamisamento, tendo o cuidado para que o novo cobrimento fosse adequado a NBR 6118 (ABNT, 2014). A classificação do elemento poderia mudar, caso o revestimento escondesse alguma patologia não observada na inspeção visual inicial. Para a recuperação ser executada, nenhum morador poderia habitar no prédio, os condôminos mudaram-se temporariamente, efetuando a retirada de móveis que auxiliou no alivio de cargas do edifício. A decisão foi difícil, já que é preciso conciliar o fator técnico e o social, mas para que o serviço fosse executado sem escoramento, seria necessária a evacuação.

A ordem de recuperação foi pilares, vigas e lajes. Foi dada a opção de ferramentas manuais, ponteira e marreta, ou mecanizadas de menor impacto para a remoção do revestimento e preparo do substrato. Escovas de aço para a elimação da ferrugem, com a aplicação de produto a base de fósforo para eliminar algum produto restante da corrosão e posteriormente aplicação de produto a base de zinco para a proteção das armaduras. Para danos localizados especificouse preenchimento com argamassa polimérica e para danos em áreas maiores, grout com resistência de 25Mpa.

\section{CONCLUSÕES}

Os conceitos apresentados, como vida útil, durabilidade e desempenho, e as patologias causadas pela ação dos cloretos na estrutura são princípios básicos para o entendimento da importância de um projeto bem planejado, detalhado e coerente em relação ao ambiente em que a estrutura está inserida.

O trabalho em equipe, com proprietário, projetista, construtor e usuário, além do monitoramento do comportamento da estrutura, são essenciais para o acúmulo de informações, e servem para fundamentar o momento de uma manutenção preventiva. Todas as instruções quanto às atividades que devem ser executadas durante a vida útil da estrutura devem estar contidas no manual. Dessa forma, essas ações irão atuar conjuntamente com o atendimento aos requisitos de qualidade e desempenho que foram corretamente especificados e acompanhados no processo de construção da obra.

A compreensão dos mecanismos de atuação dos íons cloretos sobre a estrutura são elementos básicos tanto para a elaboração de um projeto, como a elaboração de um reparo estrutural. Para a recuperação da parcela deteriorada é fundamental um correto diagnóstico com a finalidade de indicar a terapia mais adequada. Com o texto desenvolvido, foi obtida uma visão ampla do processo construtivo e do reparo, de maneira a obter estruturas de concreto duráveis. 


\section{REFERÊNCIAS}

ANDRADE, J. J. O. Durabilidade das estruturas de concreto armado: análise das manifestações patológicas nas estruturas no estado de Pernambuco. (Dissertação de Mestrado). UFRS, Porto Alegre, 1997. 148 p.

BRETT, A. M. O.; BRETT, C. M. A. Eletroquímica princípios, métodos, e aplicações. Coimbra: Livraria Almedina, 1996.

ALBUQUERQUE, Augusto; OTOCH, Sérgio. Proposta de classificação da agressividade do ambiente na cidade de fortaleza. In: CONGRESSO BRASILEIRO DO CONCRETO, 47., 2005, Recife. Anais... . Recife: Ibracon, 2005. p. 1 6.

CABRAL, A. E. B. Avaliação dos sistemas de reparo utilizados em estruturas atacadas por cloretos através da resistência de polarização. (Dissertação de mestrado). Universidade Federal do Rio Grande do Sul, Porto Alegre, 2000.

CAMPOS, A. M. R. Estudo da agressividade do ar atmosférico de Fortaleza/CE. por cloretos através da resistência de polarização. (Dissertação de mestrado). Universidade Federal do Ceará, Fortaleza, 2016.

CÁNOVAS, Manuel Fernanéz. Patologia e Terapia do Concreto Armado. São Paulo: Pini, 1988. 522 p.

CASCUDO, O. O controle da corrosão de armaduras em concreto: Inspeção e técnicas eletroquímicas. 1. ed. Goiânia: UFG, 1997. p. 39-61.

EURO-INTERNATIONAL COMMITTEE FOR CONCRETE. CEB - FIP MC 90: Design COde. Londres: Thomas Telford, 1990. $461 \mathrm{p}$.

FITZGERALD, J.W. Marine aerosols: a review. Atmospheric Environment, v. 25A, N.3/4, p. 533-545, 1991.

GJøRV, Odd E.. Projeto da durabilidade de estruturas de concreto em ambientes de severa agressividade. São Paulo: Oficina de Textos, 2015.

HELENE, P. A Nova ABNT NBR 6118 e a Vida Útil das Estruturas de Concreto. In: Seminário de Patologia das Construções, 2, 2004, Porto Alegre. Proceedings... Porto Alegre: Novos Materiais e Tecnologias Emergentes, LEME, UFRGS, 2004. v. 1. p. 1-30

HELENE, P. R. L. Contribuição ao estudo da corrosão em armaduras de concreto armado. 1993. 248 f. Tese (Doutorado) - Curso de Engenharia Civil, Usp, São Paulo, 1993.

HELENE, P. R. L. Manual para reparo, reforço e proteção de estruturas de concreto. 2. ed. SãoPaulo: Pini, 1992. p. 2760.

IBIAPINA, Juan Luís Gomes. Durabilidade de estruturas de concreto armado em ambientes com elevada concentração de cloretos. 2019. 75 f. Monografia (Graduação em Engenharia Civil) - Universidade Federal do Ceará, Fortaleza, 2019.

LAPA, José Silva. Patologia, recuperação e reparo das estruturas de concreto. 2008. 56 f. Monografia (Especialização) Curso de Engenharia Civil, Ufmg, Belo Horizonte, 2008.

NEVILLE, A. M. Propriedades do concreto. Tradução: Salvador E. Giammusso. $2^{\circ}$ ed. rev. Atual. São Paulo: Pini, 1997.

MEHTA, P Kumar; MONTEIRO, Paulo J M. Concreto, estrutura, propriedades e materiais. São Paulo: Pini, 2014.

MOLIN, Denise C C dal; SILVESTRO, Laura. Avaliação de modelos para previsão de vida útil de estruturas de concreto armado localizadas em ambientes com cloretos. In: CONFERêNCIA SOBRE PATOLOGIA E REABILITAÇÃO DE EDIFÍCIOS, 6., 2018, Rio de Janeiro. Anais... . Porto Alegre: Nppg, 2018. p. 1 - 10.

M.M. Page, C.L. Page, V.T. Ngala, D.J. Anstice, Ion chromatographic analysis of corrosion inhibitors in concrete, Construct. Build. Mater. 16 (2) (2002) 73. 
O’DOWD, C. D.; SMITH, M. H.; CONSTERDINE, I. A.; LOWE, J. A. Marine aerosol, seasalt, and the marine sulphur cycle: a short review. Atmospheric Environment, v. 31, n. 1, p. 73-80, 1997.

PIAZZOLA, J.; DESPIAU, S. Contribution of marine aerosols in the particle size distributions observed in Mediterranean coastal zone. Atmospheric Environment, v. 18, p. 2991-3009, 1997.

PONTES, Ronaldo Bezerra. Disseminação de íons cloreto na orla marítima do bairro de Boa Viagem, Recife-PE. 2006. 123 f. Dissertação (Mestrado) - Curso de Engenharia Civil, Universidade Católica de Pernambuco, Recife, 2006.

PORTELLA, Caio Sander Andrade. Avaliação da durabilidade de concretos produzidos segundo a ABNT 6118:2007 e expostos aos cloretos disseminados em névoa salina na Praia do Futuro, em Fortaleza-CE. 2013. 113 f. Dissertação (Mestrado) - Curso de Engenharia Civil, Ufc, Fortaleza, 2013.

POSSAN, E. Modelagem da carbonatação e previsão de vida útil de estruturas de concreto em ambiente urbano. 2010. Tese de doutorado (Doutorado em engenharia) - Escola de Engenharia, Programa de Pós-Graduação em Engenharia Civil, UFRGS, Porto Alegre.

R. F. Lovett (1978) Quantitative measurement of airbone sea-salt in the North Altantiv, Tellus, 30:4, 358-364, DOI: 10.3402ltellusa.v30i4.10354.

VILASBOAS, José Marcílio Ladeia. Estudo dos mecanismos de transporte de cloretos no concreto, suas inter-relações e influência na durabilidade de edificações na cidade do Salvador-BA. 2013. 323 f. Tese (Doutorado) - Curso de Engenharia Civil, Ufba, Salvador, 2013. 